\title{
Horizontal and vertical movements as predictors of foraging success in a marine predator
}

\author{
Anne-Cécile Dragon ${ }^{1,2,3, *}$, Avner Bar-Hen ${ }^{2}$, Pascal Monestiez ${ }^{4}$, Christophe Guinet ${ }^{1}$ \\ ${ }^{1}$ CEBC-CNRS, 79360 Villiers en Bois, France \\ ${ }^{2}$ MAP5-CNRS, 45 rue des Saints-Pères, 75270 Paris Cedex 06, France \\ ${ }^{3}$ LOCEAN-UPMC, 4 place Jussieu, boite 100, 75252 Paris Cedex 05, France \\ ${ }^{4}$ BioSP-INRA, Domaine Saint-Paul, Site Agroparc, 84914 Avignon, France
}

\begin{abstract}
With technical advances in wildlife telemetry, the study of cryptic predators' responses to prey distribution has been revolutionised. In the case of marine predators, high resolution tagging devices have been developed recently to collect precise diving datasets covering extended periods of time. In this study, we investigated changes in the horizontal movements and diving patterns of a marine predator, the southern elephant seal, at fine temporal and spatial scales. Satellite tracking data collected for 9 seals were processed with switching state-space models. Seal body condition, as a proxy for foraging success, was estimated through changes in drift rate from Time Depth Recorder (TDR) data. We identified (1) statistically distinct behavioural modes from the tracking data (intensive vs. extensive foraging modes) and (2) distinct dive classes from the TDR diving data (drift, exploratory, shallow active and deep active dives). Active dives, associated with vertical foraging and chasing, were more numerous when the seals were in intensive foraging mode. Improved body condition and mass gain of seals were also associated with the intensive foraging mode and, within the vertical dimension, with sets of highly active dives. In conclusion, proportions of dive classes varied according to seals' horizontal behaviour. Intensive foraging detected from surface tracking data is a good predictor of diving activity and foraging success occurring in the vertical dimension.
\end{abstract}

KEY WORDS: Area-restricted search - Dive classification - Drift dive - Fine-scale behaviour · Movement analysis

Resale or republication not permitted without written consent of the publisher

\section{INTRODUCTION}

Understanding the responses of predators to spatial and temporal variability of their prey distribution is fundamental for determining how animals may respond to global changes in their environment. The Southern Ocean is one of the most productive oceans (Smetacek \& Nicol 2005) and it has been shown that this circumpolar ocean has warmed more rapidly than the global ocean average (Gille 2002). It has also been shown that winds over this ocean have strongly increased over the past few decades (Meredith \& Hogg 2006) causing an increase in the intensity and frequency of eddy activity. This could have significant impacts on primary productivity (Le Quéré et al. 2007) and hence on feeding opportunities for predators. Nonetheless, direct observations of how marine predators interact with their environment and their prey are very scarce. Because of the Southern Ocean's remoteness, it is particularly challenging to obtain information on diet and the distribution of prey for long-ranging migratory species in these waters.

Accurate feeding indices are often difficult to obtain, and most studies use proxies instead, such as changes in movement patterns and time spent within restricted areas (Weimerskirch et al. 2007, Aarts et al. 
2008). Recent developments in animal-mounted loggers (Jouventin \& Weimerskirch 1990, Weimerskirch et al. 2002) and indirect diet analyses (Bradshaw et al. 2004) have significantly increased our knowledge of the ecology of cryptic marine predators. In particular, recordings of predators' movements, diving behaviour and in situ oceanographic parameters have indirectly contributed to a better understanding of the distribution of prey species, which is otherwise difficult to observe.

By correlating movement patterns to environmental conditions, characteristics of the areas that are profitable for a predator can be revealed (Turchin 1991). In various predator species, resource acquisition has been linked to a type of free-ranging behaviour called the area-restricted search (ARS) (Kareiva \& Odell 1987). Following capture of a prey item in a prey-aggregated environment, such as the open ocean, an animal will intensify its foraging in the patch where it caught the prey (Charnov 1976, Parker \& Stuart 1976). Therefore, an ARS is characterised by a decrease in displacement speed and an increase in the track sinuosity in areas with putative prey aggregation (Bovet \& Benhamou 1988). In contrast, between 2 patches, the animal follows a more linear track and travels at a faster pace. Natural environments are generally considered as hierarchical patch systems, in which patches at small scales are nested in patches at larger scales (Kotliar \& Wiens 1990). While foraging, predators often display movement patterns at multiple spatial and temporal scales that are assumed to match the spatial structure of the hierarchical aggregations of prey (Fauchald 1999). Prey encounter rate likely plays a major role in a predator's foraging decisions at small spatial scales, especially within a dense patch. On the other hand, past experience can be expected to mainly influence large-scale movements at a scale where prey distribution is more predictable (Hunt et al. 1999). With the latest technical advances in wildlife telemetry, it is now possible to examine small-scale movements that are crucial to a better understanding of scale-dependent adjustments in the movement of long-ranging predators. It is now possible to accurately study foraging decisions by using a high-precision locating system (GPS; Weimerskirch et al. 2002) together with high-resolution behavioural recorders, including Time Depth Recorders (TDR; Charrassin et al. 2001) and stomach temperature sensors (Austin et al. 2006). However, to understand the effects of environmental variability on the foraging success and, ultimately, increased fitness of marine predators, requires not only at-sea movement analyses, but also some method of identifying where and when the animals actually improve their body condition.

In the case of diving predators, buoyancy has been proved to directly depend on the animals' body condition (Webb et al. 1998, Aoki et al. 2011). As a predator feeds and increases its body condition, the relative proportion of adipose tissue increases, thereby increasing its buoyancy (Robinson et al. 2010). Therefore, a predator species that performs dives during which the animals drift passively in the water column is an ideal study model to inform analysis of body condition based on in situ buoyancy (Biuw et al. 2003). Travelling thousands of kilometres per year in the circumpolar waters of the Southern Ocean (McConnell et al. 1992), Southern elephant seals Mirounga leonina are elusive marine predators that can spend as much as $85 \%$ of their lifetime at sea (McIntyre et al. 2010). They continuously dive during their extended stay at sea and often display behaviour termed 'drift dives' along their track (Crocker et al. 1997). They regularly perform these dives, during which they stop swimming and drift passively in the water column (Biuw et al. 2003, Mitani et al. 2010). Vertical movements during these dives have been shown to be related to the seal's body condition (Webb et al. 1998): fat and positively buoyant seals will follow an upward drift. Inversely, lean seals with negatively buoyant body condition will sink during a drift dive. An increase in the drift rate over time is therefore an index of a successful foraging activity (Biuw et al. 2007, Bailleul et al. 2007b, Thums et al. 2008, Robinson et al. 2010). Although there are potential errors in the estimation of foraging success from drift rate, they generally lead to an underestimation of the energy gain and foraging success (Robinson et al. 2010). Southern elephant seals therefore represent a unique opportunity for studying, in situ, links between the foraging behaviour and an individual's body condition.

Horizontal foraging behaviour, from track-based analyses of low-resolution surface tracking data, has been studied in detail (Bailleul et al. 2008). However, southern elephant seals spend little time at the surface between each dive (Hindell et al. 1991) and feed on deep-ranging prey (Cherel et al. 2008). In addition, previous studies could only integrate the diving behaviour by using indices estimated from lowresolution dive profiles (4 depth-time points per dive; Biuw et al. 2003, Bailleul et al. 2007a). Recent studies have focused on fine-scale vertical behaviour, which is more likely to respond directly to prey abundance (Thums et al. 2011). However, fine-scale vertical, as well as horizontal, foraging behaviour remain poorly 
known, which limits our understanding of seals' responses to the variability in prey distribution.

In the Southern Ocean, mesoscale features, such as fronts and eddies, have been shown to have a significant impact in structuring and enhancing primary productivity (Bakun 2006). They are likely to influence the spatial structure of prey patches and play a key role in the formation of profitable foraging areas for oceanic predators (Bost et al. 2009). The interfrontal zone, between the Polar Front (PF) and the Southern Subtropical Front (SSTF) (Fig. 1), is especially dynamic with locally productive eddies that are rich in prey. Within the Kerguelen population that is the object of the present study, over two-thirds of the southern elephant seal females likely forage in the interfrontal zone (Bailleul et al. 2010a). It is therefore a key habitat, where these predators interact with spatially and temporally heterogeneous oceanographic features (Dragon et al. 2010). In this study, we used high resolution tracking and diving data to investigate fine-scale temporal and spatial changes in horizontal movements and diving patterns of female elephant seals in the interfrontal zone. We expected a good correspondence between the areas of intensive foraging identified from horizontal tracking data and the areas with high proportions of foraging dives, as determined from Time-Depth Recorder (TDR) data. Finally, using drift rate as a physiological proxy of foraging success, we monitored the gain or loss in the seals' body condition and compared this with the observed diving behaviour.

\section{MATERIALS AND METHODS}

\section{Logger deployment}

In October 2009, 9 post-breeding southern elephant seal females, all about the same mass $(296 \pm 26 \mathrm{~kg})$ and length $(236 \pm 14 \mathrm{~cm})$, were captured on the Kerguelen Islands $\left(49^{\circ} 20^{\prime} \mathrm{S}, 70^{\circ} 20^{\prime} \mathrm{E}\right)$. They were anaesthetised using a 1:1 combination of tiletamine and zolazepam (Zoletil 100) which was injected intravenously (McMahon et al. 2000). Data loggers were glued on the head of the seals, using quick-setting epoxy (Araldite AW 2101), after cleaning the fur with

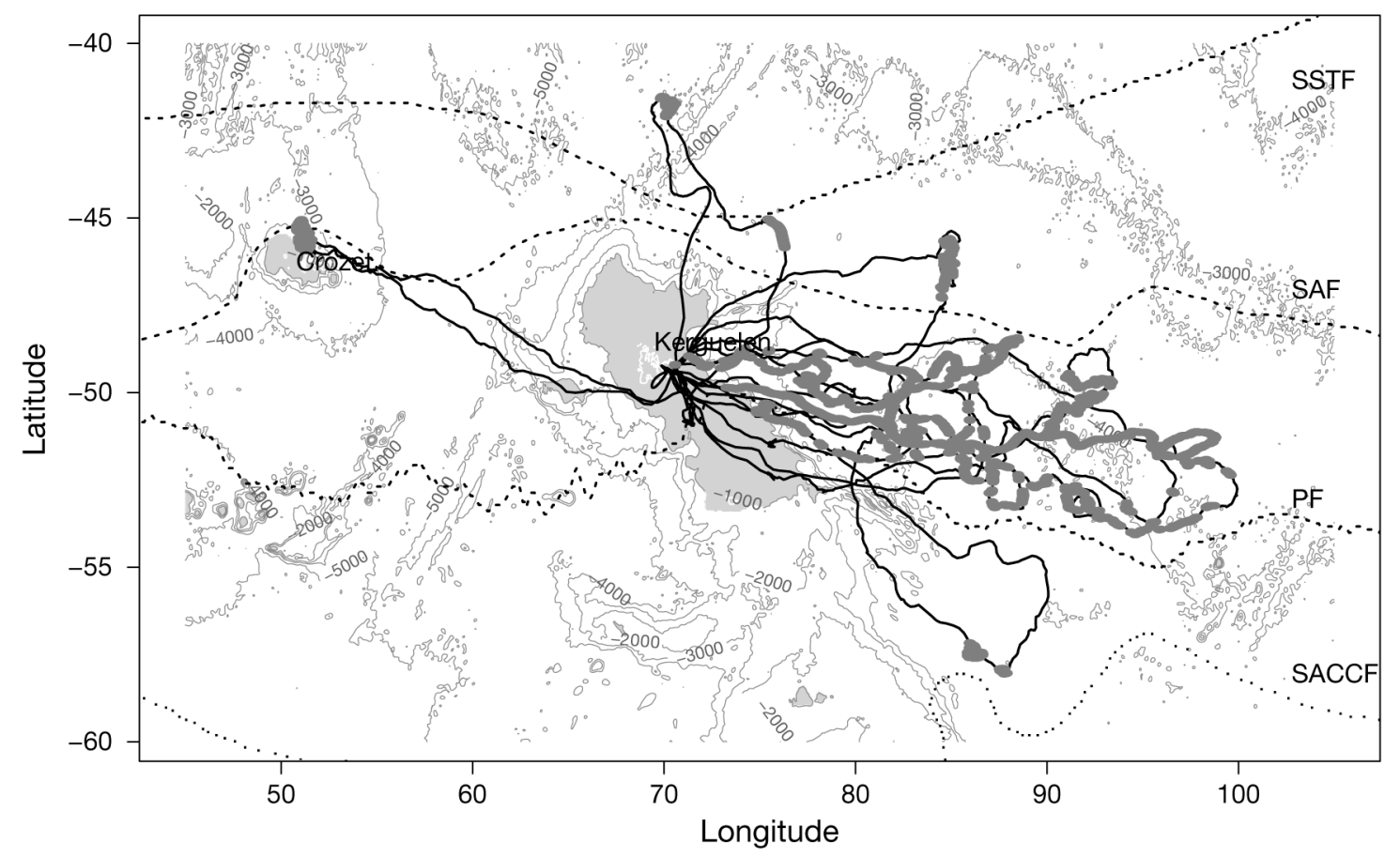

Fig. 1. Physical oceanography in the southern Indian Ocean and post-breeding foraging trips of 9 female southern elephant seals equipped with tracking devices in October 2009 (solid black lines). Light grey shading indicates depths less than $1000 \mathrm{~m}$ and depicts Kerguelen and Crozet plateaux. The coastlines of Kerguelen and Crozet islands are also indicated in white over the plateaux. Dotted lines symbolize fronts (Orsi et al. 1995) in the Southern Ocean: Southern SubTropical Front (SSTF), SubAntarctic Front (SAF), Polar Front (PF) and Southern Antarctic Circum-Polar Front (SACCF). In this study, we refer to the interfrontal zone as the area between the STF and the PF. Locations of intensive foraging behaviour displayed by the seals are indicated in dark grey dots over the tracks 
acetone. Four seals were equipped with GPS loggers in combination with Argos satellite loggers and archival data loggers (MK10 Fast-Loc, Wildlife Computers). MK10 devices transmitted Argos location data and collected GPS location data. To save battery life, the sampling interval of GPS locations was set to a minimum of $20 \mathrm{~min}$, i.e. slightly shorter than the average dive duration of the species (Hindell et al. 1991). An additional logger, a TDR included in the MK10 devices, collected and archived pressure and temperature levels every $2 \mathrm{~s}$. The other 5 seals were equipped with fluorometry-conductivity-temperature-depth satellite-relayed data loggers (Fluoro-CTD-SRDLs, Sea Mammal Research Unit, University of St Andrews) combined with MK9-TDR loggers (Wildlife Computers, Washington, USA). Fluoro-CTD-SRDL devices allowed the calculation and transmission of location estimates of Argos quality. The MK9 devices combined with Fluoro-CTD-SRDLs were set to sample and archive pressure and temperature levels every $2 \mathrm{~s}$. After their respective haulout beaches had been located via Argos data, returning females were later recaptured and weighed and loggers were retrieved.

\section{Tracking data and identification of horizontal foraging behaviour}

The GPS and Argos seal tracking data were analysed with state-space models in order to detect areas of restricted search (Jonsen et al. 2003, Patterson et al. 2008, Schick et al. 2008, Block et al. 2011). Argos locations were first estimated using the observation model of a switching-state-space model in order to take measurement errors into account (Jonsen et al. 2003). Following preliminary studies based on the movement parameters distributions (not displayed here), we used 2 behavioural modes for the analyses: intensive foraging, when ARS behaviour is displayed, versus extensive foraging, when the animal travels faster and follows a more linear path (for details see Jonsen et al. 2007, Block et al. 2011). The state-space models estimated the probability along the path of the animal being in a particular behavioural mode. GPS tracks were analysed in the same way: the switching state-space models discerned 2 behavioural modes within the location data. All models were fitted with the freely available software WinBUGS (Spiegelhalter et al. 1999) called from R (R Development Core Team 2009) using the package R2WinBUGS (Sturtz et al. 2005). As recommended by Dennis (1996), we used vague priors (Gamma and Uniform distributions). Two Monte-Carlo Markov Chains (MCMC) were run for each model, with 50000 iterations following a 25000 burn-in (thin = 2).

As female southern elephant seals from Kerguelen population are known to forage mostly in the pelagic waters of the interfrontal zone (Bailleul et al. 2010b, Dragon et al. 2010), we focused on the pelagic part of the tracks by masking data from areas where water depths were less than $1000 \mathrm{~m}$, based on National Geophysical Data Center ETOPO2 Global 2' Elevations (NGDC 2001), to exclude all locations on the Kerguelen and Crozet plateaux, and hence all benthic dives.

\section{Diving behaviour and dive classification}

The following diving variables were derived from MK9 and MK10 TDR data (Table 1): maximum depth, descent and ascent speeds, bottom-time duration (where the bottom phase starts at the end of the descending phase and finishes at the beginning of the final ascent to the surface) and bottom-time residuals (residuals of multiple regression of bottom time $\sim$ maximum dive depth + dive duration, calculated for each dive within a path; Bailleul et al. 2008) and vertical sinuosity in the bottom phase, calculated following Weimerskirch et al. (2007) as:

BottomSinuosity $=\frac{\text { BottomDistance }_{\text {observed }}}{\text { BottomDistance }_{\text {euclidean }}}$

Table 1. Behavioural variables used to analyse diving behaviour in southern elephant seals, based on analysis of Time Depth Recorder (TDR) and GPS tracking data

\begin{tabular}{|llll|}
\hline Variable & Abbreviation & Definition & Source \\
\hline Bottom-time (min) & Bott.Time & Descent end to ascent start & TDR \\
Bottom-time residuals $(\mathrm{min})$ & Res.Bott.Time & Residuals of multiple regression & TDR \\
Maximum diving depth $(\mathrm{m})$ & Max.Depth & - & TDR \\
Sinuosity & - & Derived from Weimerskirch et al. (2007) & TDR \\
Ascending speed $\left(\mathrm{m} \mathrm{s}^{-1}\right)$ & Asc.Speed & - & TDR \\
Descending speed $\left(\mathrm{m} \mathrm{s}^{-1}\right)$ & Des.Speed & - & TDR \\
Horizontal distance $\left(\mathrm{km}^{-1}\right.$ & Horiz.Dist & Distance travelled between 2 dives & GPS \\
\hline
\end{tabular}


where BottomDistance observed $_{\text {is }}$ the total vertical distance swum in the bottom of the dive, and BottomDistance euclidean $_{\text {is }}$ the sum of the Euclidean distances from the depth at the beginning of the bottom phase to the maximum depth and from the maximum depth to the depth at the end of the bottom phase. Vertical sinuosity takes a value of 1.0 when the animals swims in a straight path at the bottom of its dive. Any deviation from a straight path increases the sinuosity value. The horizontal distance travelled during each dive was also estimated from linearly interpolated GPS tracking data. Drift dive identification was processed from the complete time-depth (TDR) data in 3 steps: (1) Instantaneous vertical speed was calculated from the timedepth data. (2) Vertical speed was then smoothed by using a moving average filter (10 s window) in order to compensate for abrupt changes in depth reading due to the sensor accuracy $( \pm 1 \mathrm{~m})$. (3) Within dives, drift phases were isolated using a custom-made function under R software (R Development Core Team 2009). Drift phases were detected as periods of time of more than 3 min during which the vertical speed was bounded between $[-0.6 ; 0.6] \mathrm{m} \mathrm{s}^{-1}$ and with a low variance $\left(s^{2}<0.005\right)$ (for more details see the annotated $R$ codes in the supplement at www.int-res.com/articles/ suppl/m447p243_supp/). For each drift dive, a drift rate was determined as the slope coefficient of a linear regression between depth and time (Biuw et al. 2003, Bailleul et al. 2007a, Mitani et al. 2010). Daily averaged drift rates were calculated for the 3-mo tracks.

Following a preliminary analysis of diving behaviour (Table 1) and a literature review (Hindell et al. 1991, Schreer et al. 2001, Hassrick et al. 2007), 4 dive classes displayed by the seals in pelagic waters were determined. A k-mean classification was then applied to the normalised Principal Component Analysis ( $\mathrm{PCA}_{\text {; }}$ with 4 principal components) scores from the behavioural variables of all individuals in the pelagic part of their tracks (Forgy 1965). Transition matrices showing the probabilities of changes from one dive class to another were then estimated. The daily proportions of the 4 dive classes were also calculated for each individual. Linear mixed models, with individual as random effect, were used to evaluate the daily proportions of dive class in intensive foraging versus extensive foraging areas detected from the tracking data. We carried out these analyses in $\mathrm{R}$ using the non-linear mixed effects (nlme) package from Pinheiro \& Bates (2000) with the residual maximum likelihood (REML) method. Model assumptions were verified and no autocorrelation or heterogeneity of variance of within-group residuals was noticed (Pinheiro \& Bates 2000).

\section{Detection of successful foraging areas with drift rate increases and mass gain models}

Positive variations of drift rate are assumed to indicate an improvement of the seal's body condition and buoyancy (Crocker et al. 1997, Biuw et al. 2003). We therefore used increases in drift rate as a physiological index of successful foraging activity along the seals' tracks. The overall drift rate increase was calculated as the difference between the mean drift rate $\left(\mathrm{m} \mathrm{s}^{-1}\right)$ over the last $10 \%$ of the track, hereafter referred as the final drift rate, and the mean drift rate over the first $10 \%$ of the track. Final drift rate before hauling-out and percentage of time spent in intensive foraging were also considered. We also calculated the respective proportions of the 4 dive classes displayed during intensive and extensive foraging. For all individuals, mass gain $(\mathrm{kg})$ over the foraging trip was related, using linear models, to overall drift rate, final drift rate and the proportions of dive classes while in intensive foraging. Finally, we used linear models to estimate the mass gain from multiple regressions of the variables listed above. Model selection was based on Akaike Information Criterion (AIC; Akaike 1973), with a correction for small sample sizes (Burnham \& Anderson 2002), to find the best linear model (Venables \& Ripley 2002).

\section{RESULTS}

\section{Horizontal tracking data}

Argos tags transmitted on average (mean $\pm \mathrm{SD}$ ) $6.86 \pm 4.31$ locations per day whereas GPS tags collected $38.28 \pm 10.57$ daily locations. The 9 animals equipped for this study spent $79 \pm 6 \mathrm{~d}$ at sea with $69 \pm$ $9 \mathrm{~d}$ in the pelagic area. They covered an average total of $4399 \pm 622 \mathrm{~km}$, including $3822 \pm 763 \mathrm{~km}$ in pelagic waters (Fig. 1). All but one individual foraged exclusively within the interfrontal zone east of the Kerguelen Islands. The remaining one went to the western interfrontal zone, near the Crozet Plateau. Individual seals dived on average 64 times per day which is consistent with the literature (Boyd \& Arnbom 1991). This provided $5059 \pm 700$ dives per seal, of which $4529 \pm$ 909 were in pelagic waters. From the state-space model analysis, seals displayed 2 statistically distinct behavioural movement modes: intensive and extensive foraging. Intensive foraging corresponds to the display of ARS behaviour and seals were estimated to be in this mode during $33 \pm 12 \%$ of their time at sea $(28 \pm 9 \mathrm{~d})$ and in pelagic waters $(23 \pm 8 \mathrm{~d})$. 


\section{Characterisation and localisation of the dive classes}

For all individuals, 4 dive classes were detected and defined as: drift, exploratory, shallow active and deep active dives. The biological meanings of the dive classes will be discussed in detail in the first part of the discussion. Characteristics of the 4 dive classes are illustrated in Fig. 2 and Table 2. Although their relative proportions varied, with for instance deep

(a) Bottom time residuals by dive class

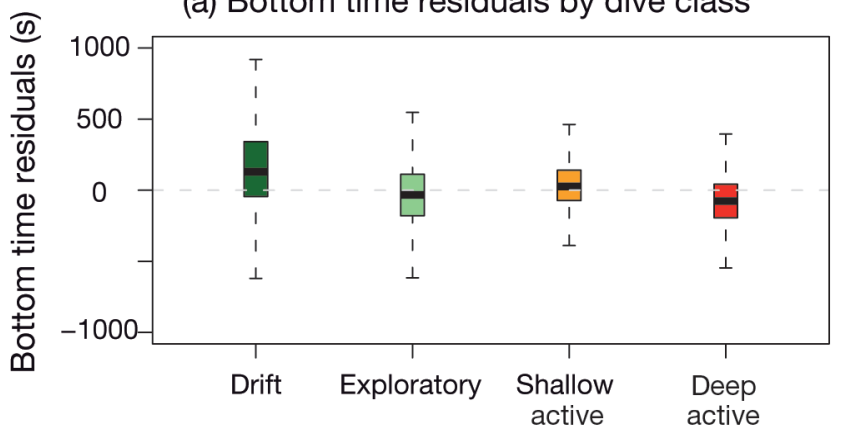

(c) Bottom time * maximum of depth

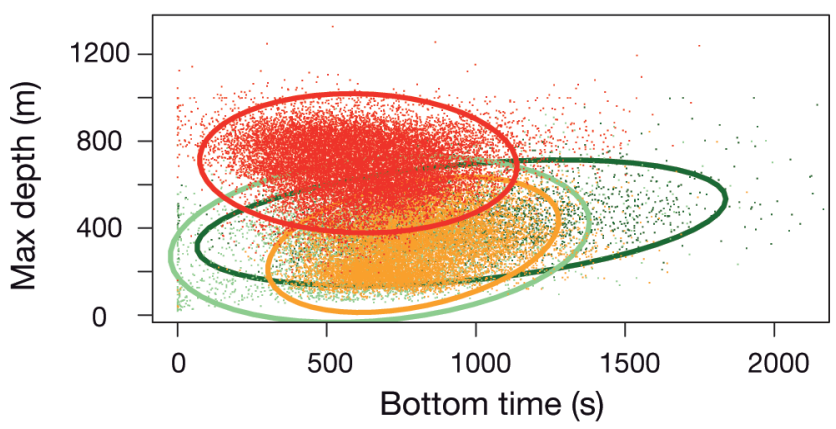

(e) Descending speed by dive class

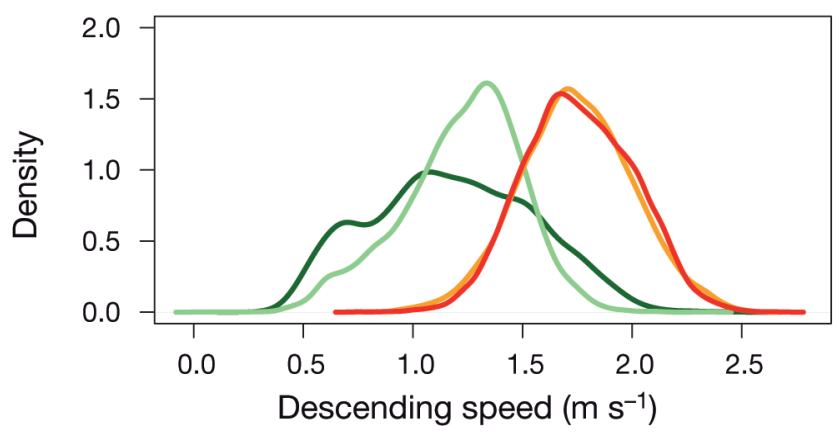

active dives being more numerous by day than by night, all dive classes were observed by day and night (Fig. 2b). Drift dives were the least sinuous in the bottom (Fig. 2d), presented the longest bottom time durations (Fig. 2a,c) and low horizontal distances (Fig. 2f). While drift diving, the animals displayed low descent (Fig. 2e) and ascent speeds (Fig. 2d); they performed this class of dive at average depths (Fig. 2c, Table 2). In contrast, deep active and shallow active dive classes exhibited high sinuosity (b) Proportions of dive classes

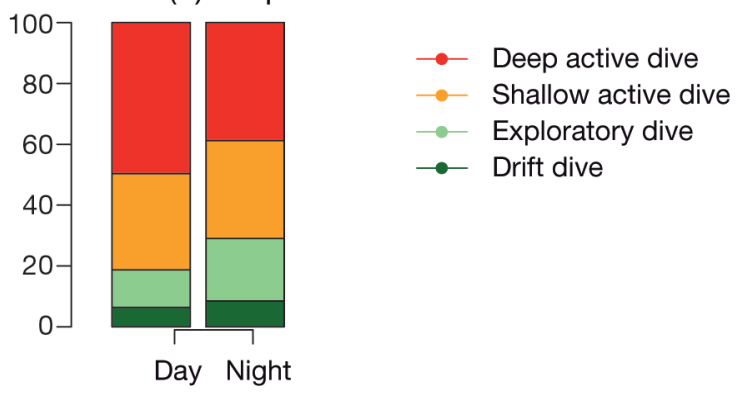

(d) Ascending speed * bottom sinuosity

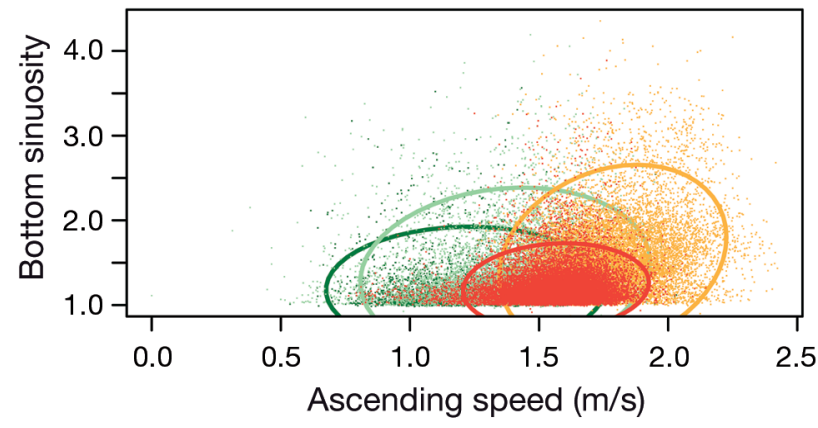

(f) Horizontal distance by dive class

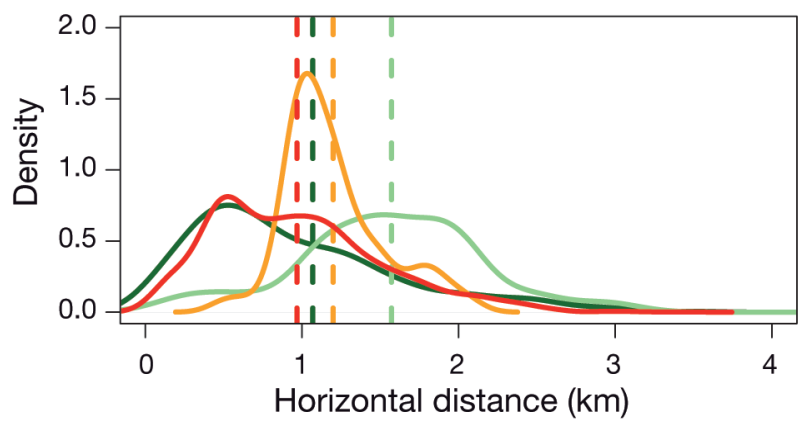

Fig. 2. Mirounga leonine. Characteristics of dive classes based on pooled data for all individuals: drift dives (dark green), exploratory dives (light green), shallow active dives (orange) and deep active dives (red). (a) Bottom time residuals (calculated as in Bailleul et al. 2008). Black bars: median; box: upper and lower quartiles; whiskers: range of values. (b) Proportional occurrence of dive classes by day and night. (c) Maximum diving depth as a function of bottom time (one point per dive and confidence ellipse of $95 \%$ ): depending on maximum diving depth, time spent at the bottom of a dive varies from one dive class to another. (d) Sinuosity at the bottom of the dive as a function of ascending speed (one point per dive and confidence ellipse of $95 \%$ ): the higher the sinuosity, the greater the ascending speed. (e) Density distributions of descending speeds. (f) Distributions of horizontal distances travelled during the dives. The dashed vertical lines indicate, for each dive class, the average 
Table 2. Mirounga leonine. Characteristics of dive classes, based on pooled tracking data data for 9 southern elephant seals. Means \pm SE are shown. All differences between the dive classes are statistically significant $(\mathrm{p}<0.001)$. See Table 1 for explanation of abbreviations

\begin{tabular}{|lcccccccc|}
\hline Dive class & $\mathrm{N}$ & $\begin{array}{c}\text { Bott.Time } \\
(\mathrm{min})\end{array}$ & $\begin{array}{c}\text { Res.Bott.Time } \\
(\mathrm{min})\end{array}$ & $\begin{array}{c}\text { Max.Depth } \\
(\mathrm{m})\end{array}$ & $\begin{array}{c}\text { Sinuosity } \\
\text { Asc.Speed } \\
\left(\mathrm{ms}^{-1}\right)\end{array}$ & $\begin{array}{c}\text { Des.Speed } \\
\left(\mathrm{ms}^{-1}\right)\end{array}$ & $\begin{array}{c}\text { Horiz.Dist } \\
\left(\mathrm{km}^{2}\right)\end{array}$ \\
\hline Drift & 2846 & $15.8 \pm 6.0$ & $2.6 \pm 5.9$ & $424 \pm 118$ & $1.19 \pm 0.29$ & $1.21 \pm 0.22$ & $1.18 \pm 0.37$ & $0.98 \pm 0.74$ \\
Exploratory & 6221 & $11.3 \pm 4.8$ & $-0.6 \pm 4.7$ & $348 \pm 156$ & $1.21 \pm 0.20$ & $1.31 \pm 0.24$ & $1.22 \pm 0.27$ & $1.57 \pm 0.67$ \\
Shallow active & 12482 & $13.2 \pm 3.3$ & $0.7 \pm 2.8$ & $324 \pm 127$ & $1.56 \pm 0.44$ & $1.77 \pm 0.19$ & $1.74 \pm 0.26$ & $1.20 \pm 0.32$ \\
Deep active & 17656 & $10.1 \pm 3.6$ & $-1.2 \pm 3.2$ & $698 \pm 131$ & $1.39 \pm 0.40$ & $1.56 \pm 0.15$ & $1.76 \pm 0.25$ & $0.97 \pm 0.54$ \\
\hline
\end{tabular}

ratio during their bottom phases (Fig. 2d). The shallow active dive class was the most sinuous of all dive classes. Both shallow and deep active classes also exhibited high descent and ascent speeds (Fig. 2d,e). Deep active dive also presented the lowest horizontal distance travelled between 2 dives of this class (Fig. 2f). Finally deep active dive class was also characterised by negative bottom-time residuals, that is, bottom times lower than expected. Considering the exploratory dive class, they were characterised by
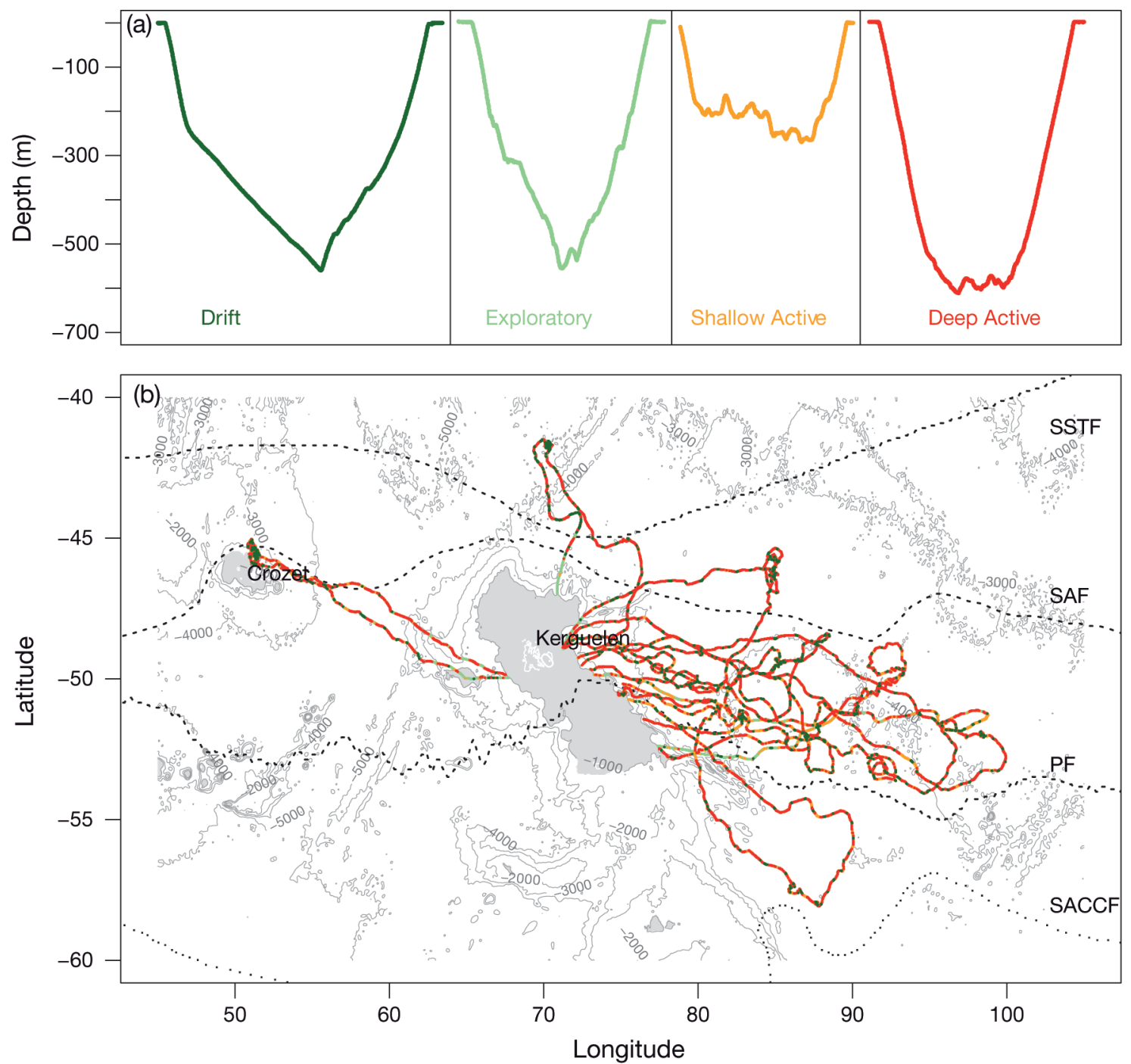

Fig. 3. Mirounga leonine. (a) Typical depth-time profiles of the 4 dive classes. (b) Locations of the dives along the seals' tracks. Red dots correspond to deep active dives, orange to shallow active dives, light green to exploratory dives and dark green to drift dives. All dive classes occurred all along the tracks, by day and by night 
Table 3. Mirounga leonine. Proportions (\%) of dive classes performed by 9 southern elephant seals equipped with tracking devices in October 2009. Only dives located in the pelagic part of the tracks were classified. For all individuals, means \pm SE are shown

\begin{tabular}{|lcccccc|}
\hline Individual & $\mathrm{N}$ & Drift & $\begin{array}{c}\text { Explora- } \\
\text { tory }\end{array}$ & $\begin{array}{c}\text { Shallow } \\
\text { active }\end{array}$ & $\begin{array}{c}\text { Deep } \\
\text { active }\end{array}$ & $\begin{array}{c}\text { Total } \\
\text { active }\end{array}$ \\
\hline $09-78524$ & 2605 & 14.8 & 9.6 & 2.5 & 73.1 & 75.6 \\
$09-78525$ & 4169 & 9.4 & 12.2 & 28.8 & 49.6 & 78.4 \\
$09-86372$ & 5778 & 5.3 & 15.5 & 41.4 & 37.8 & 79.2 \\
$09-86373$ & 4325 & 9.2 & 12.2 & 47.3 & 31.3 & 78.6 \\
ft03-Cy1-09 & 4219 & 4.6 & 24.6 & 34.2 & 36.6 & 70.8 \\
ft03-Cy2-09 & 4843 & 5.9 & 6.7 & 41.5 & 45.9 & 87.4 \\
ft03-Cy4-09 & 4889 & 5.9 & 12.5 & 42.9 & 38.7 & 81.6 \\
ft03-Cy5-09 & 5450 & 5.6 & 31.3 & 32.9 & 30.2 & 63.1 \\
ft03-Cy11038-09 & 4485 & 8.1 & 9.8 & 10.2 & 71.9 & 82.1 \\
All individuals & 40763 & $7.7 \pm 3.2$ & $14.9 \pm 7.9$ & $31.3 \pm 15.4$ & $46.1 \pm 16.1$ & $77.4 \pm 7.0$ \\
\hline
\end{tabular}

(slope(Hor.Dist) $=-0.26 \pm 0.03$, $\mathrm{p}<0.0001$ ) and a positive link with the intensive foraging mode $($ slope $(\mathrm{ARS})=5.32 \pm 2.35$, $\mathrm{p}=0.02)$. Furthermore, the most parsimonious linear mixed model of the daily proportions of drift dives showed a positive intercept (intercept $=5.91 \pm$ 1.28, p $<0.0001$ ), and positive links with the proportion of shallow dives (slope (Shallow. Active) $=0.03 \pm 0.01, p=0.03$ ) and the intensive foraging mode $($ slope $(A R S)=1.37 \pm 0.73$, $\mathrm{p}=0.05$ ). Results (Fig. 4a,b) confirmed the variations in pro-

large horizontal distance (Fig. 2f), medium vertical sinuosity at the bottom of the dives (Fig. 2d) and low descent speed (Fig. 2e). Fig. 3a presents the typical profiles of the 4 dive classes.

The proportions of dive classes along the pelagic part of the individual tracks are presented in Table 3. Overall, inter-individual variability can be noticed. However, deep active dives represent the majority of the dives (46.1\% on average) while shallow active and exploratory dives are the second and third most frequent classes with respectively 31.3 and $14.9 \%$ of the dives. Finally, drift dives are sparsely represented $(7.7 \%)$. The deep and shallow active classes together (hereinafter active dives) represent over threequarters of all dives $(77.4 \%)$. All dive classes occurred all along the tracks (Fig. 3b). On the other hand, observed probabilities of changes between dive classes from time $t$ to time $(t+1)$ revealed a high temporal persistence (i.e. temporal auto-correlation) in the animals' behaviour and a hierarchy among the dive classes (Table 4). An animal displaying a shallow active dive is most likely to continue displaying this class of dive or, if it changes, this will most likely be to a deep active dive or an exploratory dive. portions of the 4 dive classes between the 2 behavioural movement modes detected on the tracking data: extensive (Fig. 4a) and intensive (Fig. 4b) foraging. The proportion of exploratory dives almost doubles in extensive foraging areas compared to intensive ones. Meanwhile, number of drift dives is reduced nearly $50 \%$ in extensive foraging areas. The proportion of deep active dives remains identical while the proportion of shallow active dives increases with the intensification of the foraging behaviour. Therefore, the proportion of active dives, considering both deep and shallow active dives, is greater in intensive foraging areas than in extensive ones.

\section{Mass gain related to an increase in drift rate and active dives}

Mass gain ranged from -60 to $120 \mathrm{~kg}$ (Fig. 5) and was positively related to 4 variables. The overall change in drift rate along the track, referred as the gain in drift rate $(\rho=0.83, p=0.006$, Fig. $5 a)$, and the final drift rate $(\rho=0.78, p=0.013$, Fig. 5a) were positively related to the mass gain. The proportion of

\section{Combining horizontal foraging behaviour identified from tracking data to fine-scale vertical behaviour}

The most parsimonious linear mixed model of the daily proportions of shallow active dives showed a positive intercept (intercept $=42.11 \pm 5.42$, $\mathrm{p}<0.0001$ ), a negative link with the daily horizontal distance travelled
Table 4. Mirounga leonine. Observed probabilities of dive class changing from dive at time $t$ to dive at time $(t+1)$

\begin{tabular}{|lcccc|}
\hline Dive class & $\begin{array}{c}\text { Drift } \\
(t+1)\end{array}$ & $\begin{array}{c}\text { Exploratory } \\
(t+1)\end{array}$ & $\begin{array}{c}\text { Shallow active } \\
(t+1)\end{array}$ & $\begin{array}{c}\text { Deep active } \\
(t+1)\end{array}$ \\
\hline Drift $(t)$ & 0.70 & 0.12 & 0.05 & 0.13 \\
Exploratory $(t)$ & 0.06 & 0.60 & 0.19 & 0.15 \\
Shallow active $(t)$ & 0.01 & 0.09 & 0.76 & 0.14 \\
Deep active $(t)$ & 0.02 & 0.05 & 0.11 & 0.82 \\
\hline
\end{tabular}




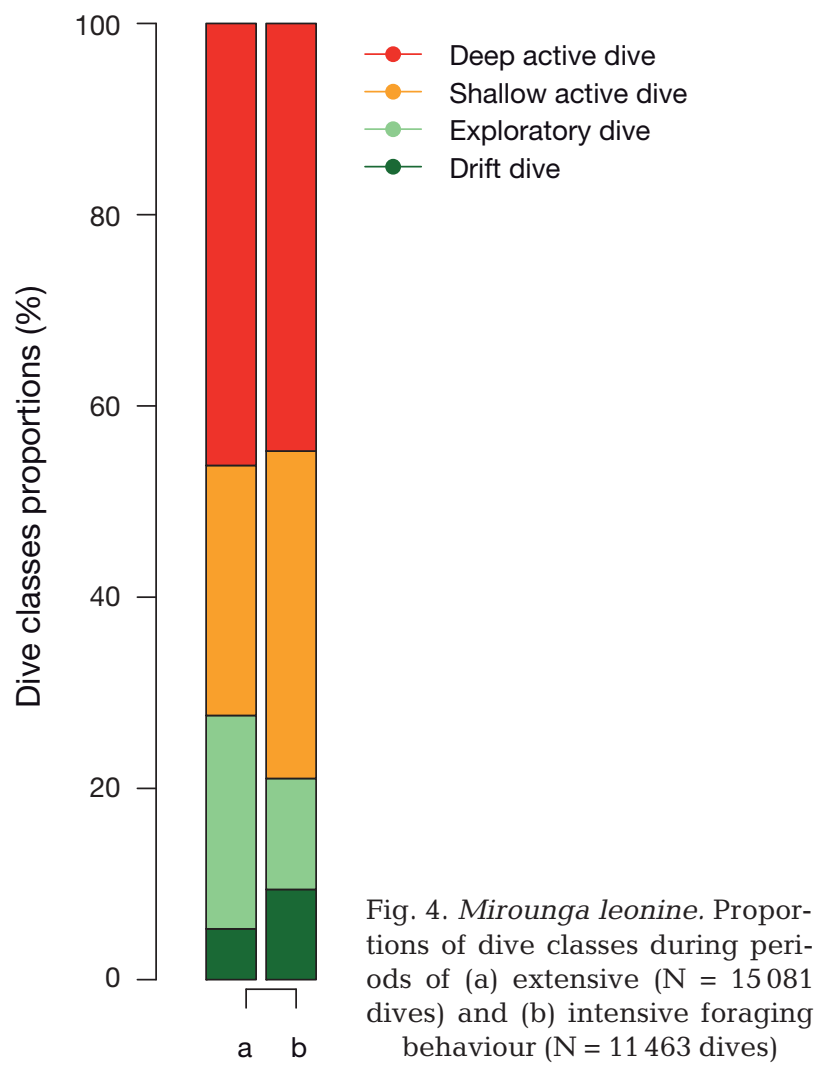

time spent in intensive foraging $(\rho=0.67, p=0.049$, Fig. $5 \mathrm{~b}$ ) and the proportion of active dives realised while the animal was in intensive foraging $(\rho=0.80$, $p=0.009$, Fig. $5 b$ ) were also positively related to the mass gain. The drift rate gain was the variable best correlated with mass gain. The model selection, based on small-sample-size-corrected AIC (AICC) and applied to multiple regressions (Table 5), identified the most parsimonious model: Mass Gain Drift Rate Gain $\left(\mathrm{AICc}=65.99, \mathrm{R}^{2}=0.685\right.$, with slope $=$ $708.26 \pm 181.54$ and intercept $=-110.75 \pm 42.82$ ). It is to be noted that the second most parsimonious is:
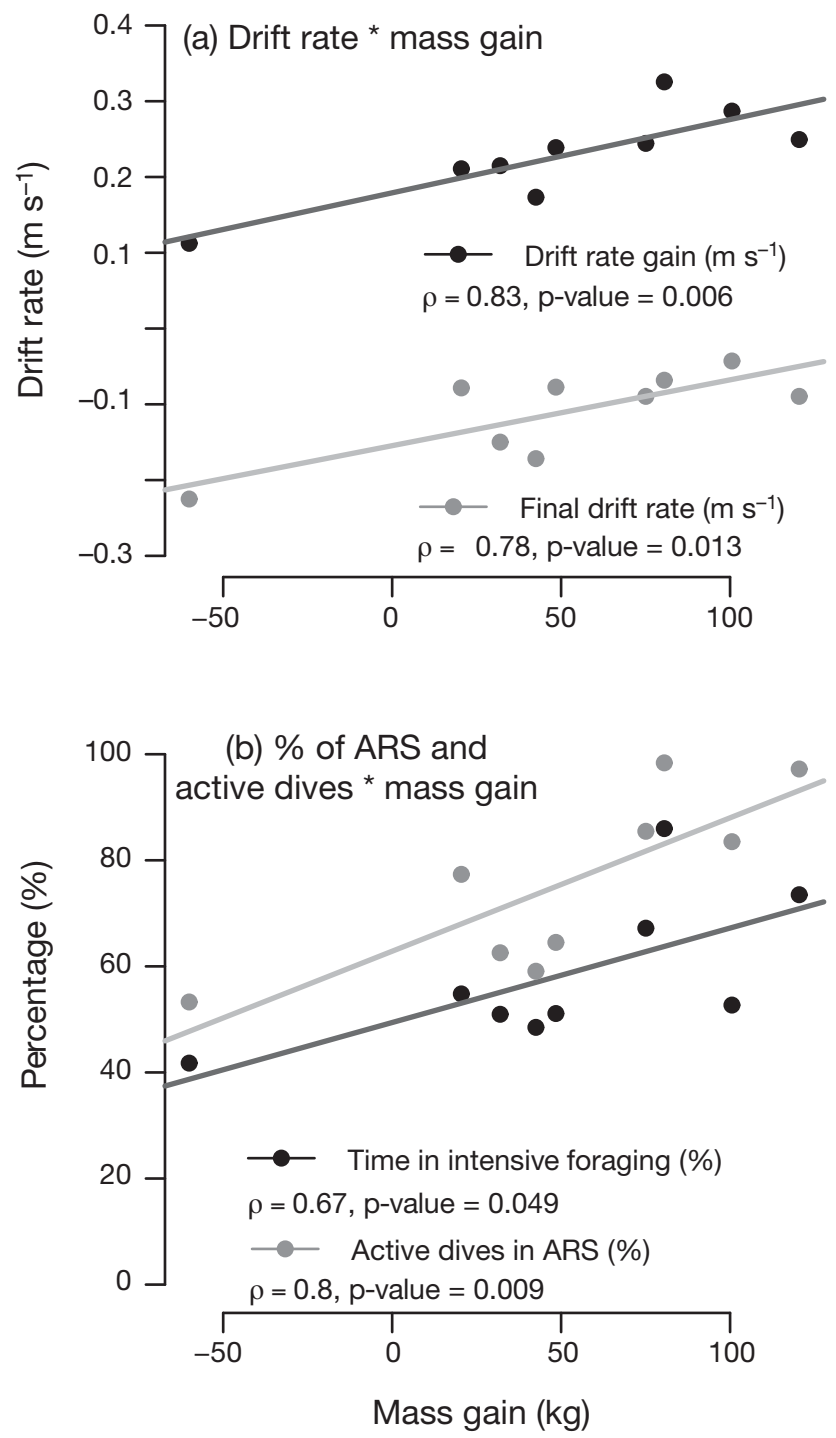

Fig. 5. Mirounga leonine. Mass gain plotted against (a) overall and final drift rates; and (b) percentage of time spent in intensive foraging. and proportion of active dives performed in intensive foraging mode. Lines correspond to the significant linear regressions between variables

Table 5. Mirounga leonine. Model selection based on small sample size corrected Akaike Information Criterion (AICc; Akaike 1973). The model with the smallest AICc value is considered the best. The variable to explain is the gain in mass over the animal's foraging trip (MassGain) and the tested variables are: the animal mass when captured before the post-breeding foraging trip (MassStart), the gain in drift rate over this trip (DriftRateGain), the final drift rate (FinalDriftRate), the percentage of intensive foraging mode in pelagic waters (PropARS) and the percentage of active dives performed while the animal was in intensive foraging mode (PropActiveARS)

\begin{tabular}{lr} 
Model formula & AICC \\
\hline MassGain MassStart + DriftRateGain + FinalDriftRate + PropARS + PropActiveARS & 111.25 \\
MassGain MassStart + DriftRateGain + PropARS + PropActiveARS & 87.27 \\
MassGain MassStart + DriftRateGain + PropActiveARS & 75.61 \\
MassGain DriftRateGain + PropActiveARS & 69.47 \\
MassGain DriftRateGain & 65.99
\end{tabular}


Mass Gain + Drift Rate Gain + Proportion Active Dives in ARS $\left(\mathrm{AICC}=69.47\right.$ and $\left.\mathrm{R}^{2}=0.728\right)$.

\section{DISCUSSION AND PERSPECTIVES}

In this study, we showed that intensive foraging detected from surface tracking data is a good predictor of the diving activity and foraging success occurring in the vertical dimension. Previous studies have shown that southern elephant seals display several dive classes during the pelagic parts of their foraging trips (Hindell et al. 1991, Schreer et al. 2001, Thums et al. 2008). However, only few studies linked the fine-scale diving patterns with the horizontal movements detected from high resolution tracking data (e.g. Thums et al. 2011). Our results suggest that proportion of active dives is greater when seals are displaying area-restricted search behaviour than when they are extensively foraging. Our study also highlights that the mass gain over the animals' foraging trip is positively correlated to increasing drift rate and to the proportions of active dives and intensive foraging detected from tracking data.

\section{Characterisation and ecological role of dive classes}

In the pelagic waters of the interfrontal zone, all individuals displayed 4 distinct dive classes. For all individuals but one (09-78524, Table 3), drift dives were the least abundant dives. As first mentioned by Hindell et al. (1991), drift dives occurred in bouts generally in the early hours of the morning and are thought to be resting and/or food processing dives (Crocker et al. 1997, Mitani et al. 2010). For some individuals, we also noticed a high occurrence of drift dives after long sets of deep active dives (results not shown). Thums et al. (2008) observed a tendency of positively buoyant seals to display upwards drift phases in their foraging dives, leading to their misclassification as drift dives. Because our study was based on post-breeding foraging trips that are much shorter (ca. $3 \mathrm{mo}$ ) than post-moulting ones (ca. $7 \mathrm{mo}$ ), only one seal reached positive buoyancy. Therefore, misclassification of the dives was not problematic in our study.

High sinuosity, corresponding to wiggle displays in the bottom phase, combined with a maximisation of the time spent at the bottom of the dive (i.e. high descent and ascent speeds) can be associated with intensively active foraging (Fedak et al. 2001). Both deep and shallow active dives are very abundant, occur in bouts or series and generally have a uniform depth within a bout. Finally, deep active dives were characterised by negative bottom-time residuals, indicating dives with short bottom duration in comparison with their maximum depths. A large degree of vertical sinuosity, fast descending and ascending speeds combined to negative bottom-time residuals highlight the very high energetic demand of this dive class. Shallow active dives presented slightly positive bottom-time residuals, indicating a longer time than expected spent at the bottom phase, which has been presented in previous studies as a proxy for intensive foraging (Bailleul et al. 2007b). Considering the time spent at the bottom, female elephant seals seem to display a trade-off between foraging intensity and depths at which foraging occurs. Since bottom-time residuals are calculated with a linear multiple regression (Bailleul et al. 2007b, 2008), it seems plausible that at deep depths, where the deep active dives occur, the relation between dive duration and maximum depth changes. The inflection of this relation would therefore lead to the sign inversion observed in bottom-time residuals between the deep and shallow active dives. In shallow active dives, seals would optimise their efficient hunting time in maximizing the proportion of time spent at the bottom of their dives where prey may be encountered, hence displaying positive bottom-time residuals (Schreer et al. 2001). In contrast, while deep-diving, seals' abilities for bottom-time adjustment are reduced by long descending and ascending periods. In the end, both active dive classes are likely to represent intensive foraging activity and similar square dives have been described in previous studies on various diving predators (LeBoeuf et al. 1988, Hindell et al. 1991, Schreer \& Testa 1996, Fedak et al. 2001, Schreer et al. 2001, Hassrick et al. 2007). Therefore, in our study, vertical sinuosity at the bottom was an important predictor of the dive class, as speed and depth were in other classification studies of southern elephant seals (Hindell et al. 1991, Thums et al. 2008).

Exploratory dives exhibited large horizontal distances and low bottom time residuals. These dives are thought to be travelling dives because the seals dive at average depths, without displaying much wiggle activity (low sinuosity in the bottom), with low-speed descent and ascent phases, and typically follow a straight path (large horizontal distance). All these characteristics also describe the V-shape dives detected in previous studies (Schreer et al. 2001).

Although southern elephant seal females from Kerguelen forage mainly in pelagic waters (Dragon et al. 
2010, Bailleul et al. 2010b), it has been shown that females of this species can dive and forage over continental shelves (Hindell et al. 1991). In this case, they may interact with different oceanographic conditions and display other foraging behaviours, resulting in additional dive classes. As a result, our data probably correspond to a subset of the dive class spectrum displayed by foraging seals. All seals in this study were females, so additional work on the finescale diving behaviour of males is needed.

\section{Association of horizontal foraging patterns with vertical behaviour and overall successful foraging}

Our results indicate that southern elephant seals display ARS over $30 \%$ of their time spent at sea and mainly within pelagic waters. From previous tracking studies, southern elephant seals are known to be predators that prospect continually within and between prey patches (Bailleul et al. 2008, McIntyre et al. 2011). This may be especially true for pregnant phocid females that exhibit a capital-breeding strategy. Phocids accumulate energy stores prior to fasting during month-long haul-out for parturition or moult (Berta et al. 2006). Between fasting periods during parturition and moult, pregnant southern elephant seal females, on their 3-mo post-breeding foraging trip, probably optimise their foraging to recover from breeding and prepare the next energetically demanding period of haul-out. All seals in this study showed a large proportion of active dives and these occurred along the entire pelagic part of their tracks by day and night. This confirms that seals are foraging and probably feeding all along their tracks and suggests that, typically, the intensification of their search in a particular zone corresponds to encounters with high quality prey patches. Seals were also found to modify the proportion of dive classes according to the behavioural mode: while intensively foraging, there was increased representation of active dive classes, i.e. of the most energetically demanding dives (high vertical sinuosity and high ascent speed). The shift between intensive and extensive foraging behaviour did not affect in the proportion of deep active dives, which remained the same, but was associated with an increased proportion of shallow active dives. From a physiological point of view, numerous deep dives that require intense foraging activity could be too demanding in terms of recovery time (Costa et al. 2004), as suggested by the fact that sets of deep active dives are followed, for some individuals, by sets of drift dives.
Therefore, the proportion of deep active dives in intensive and extensive foraging areas (ca. 45\%) could be an average threshold of southern elephant seals' ability to dive deeply and actively without energetic pay-off (Davis et al. 2001, Costa et al. 2004).

Differences in the respective proportions of the 2 active dive classes were observed between day and night. But since both were observed during day and night, a diel pattern alone cannot account for the existence of 2 active dive classes. As well as diving physiology, a combination of biologic and oceanographic factors can provide an explanation. Previous studies have shown that female southern elephant seals feed on myctophids in the interfrontal zone (Ducatez et al. 2008, Cherel et al. 2008). Myctophids are bioluminescent cryptic fish and their habitat is highly dependent on light level (Widder 2010). They adjust their habitat depth according to the light intensity and display not only nycthemeral migrations but also migrations in the water column in response to local light attenuation (which is affected by the concentration of particles in the surface water layers, cloud cover, moonlight intensity, etc.). Furthermore, the pelagic waters of the interfrontal zone include a variety of water masses (subtropical, subantarctic, polar water masses etc.) that host different prey species for southern elephant seals. The variety in prey, and in their respective habitats, potentially drives different foraging behaviours. Interfrontal zones are characterised by high levels of biological production and are frequently the site of intense mesoscale eddies (Bakun 2006). Vertical movement of water masses associated with cold-core eddies can induce isopycnal shoaling that is likely to influence prey behaviour, driving upward migrations in order to remain at preferred densities and temperatures (Wiebe 1982). Cold water and high biomass in the surface layers may cause a decrease of luminosity contributing to the presence of the cryptic myctophid species at shallower depths (Flierl \& McGillicuddy 2002). Upward cold water masses, often at the core of cyclonic eddies and at the edges of anticyclonic eddies (Bakun 2006), have been found to be preferential marine structures for foraging predators (Bost et al. 2009, Bailleul et al. 2010b, Dragon et al. 2010). Female southern elephant seals were clearly shown to intensify their diving effort and decrease their diving depth in rich upwelling areas (Dragon et al. 2010). Therefore, the existence of 2 active dive classes can be interpreted as a direct adaptation to the highly dynamic and heterogeneous pelagic environment where the seals forage. 
On the other hand, the increased proportion of shallow active dives in areas of intensive foraging likely highlights the increased accessibility of prey in the water column as observed in previous studies (Dragon et al. 2010). Myctophids migrate to shallower depths in cyclonic cores and at anticyclonic edges, and we can therefore expect seals to make higher proportions of shallow active dives in these zones. Proportions of drift dives also varied accordingly: while foraging intensively, seals made more drift dives. This could highlight their need, after numerous active dives, to rest or process food (Biuw et al. 2003). In contrast, when the seals are foraging extensively and making numerous exploratory dives, there is a decrease in the proportion of drift dives. This suggests either that seals consume less energy during exploratory dives and thus have less need to rest; or, simply, that they have less need to process food. Either way, the ultimate proxy for seals' overall foraging success, mass gain, was significantly correlated with the percentage of intensive foraging mode and of active dives while in intensive foraging: the more numerous the active dives while intensively foraging, the more successful the foraging seals. Although we worked on a 1-yr sample, similar results were found in a multi-year study by Robinson et al. (2010) that included numerous post-moulting and post-breeding tracks of northern elephant seals. It should finally be noted that these significant correlations highlight the pertinence of the proxies for predicting the foraging success of seals at the track scale. Our sample of post-breeding females was selected to be homogeneous in mass and length so that the females could be assumed to have similar age and amount of experience. All went to forage in the interfrontal zone but displayed, a variety of mass gain at the end of the study, ranging from a loss of $60 \mathrm{~kg}$ to a gain of more than $100 \mathrm{~kg}$ in only 3 mo. This high inter-individual variability in mass gain probably derives from fitness variability related to interindividual variations in foraging behaviour and/or differences in prey selection (Field et al. 2004, 2007). This confirms the importance of the individual foraging efficiency, and of past experience, in this dynamic and unpredictable oceanographic environment (Hindell et al. 1999, Bradshaw et al. 2004).

\section{Methodological perspectives}

Direct information on prey distribution in the Southern Ocean remains very scarce. Therefore, identifying periods of intensive foraging appears to be an efficient way to investigate the prey distribution of marine predators. Animal behaviour, in the horizontal and the vertical dimension, can be modelled as a dynamic variable that responds to changes in the animal's internal condition and/or its environment (Morales et al. 2004, Jonsen et al. 2007). Trackbased analyses of fine-scale vertical behaviour could be an interesting next step to investigate relationships between seals' behaviour and their environment. This could be used to systematically detect behavioural transitions along the dive profiles, associate them with the animal's immediate surroundings and infer information on prey distribution.

On the other hand, difficulties arise when interpreting 2-dimensional data (time and depth) to investigate behaviour occurring in 4-dimensions (time-longitude-latitude-depth, Thums et al. (2008)). Brillinger \& Stewart (1997) have shown that a timedepth curve can actually correspond to different possible 4D paths. We can therefore expect similar differences between the observed horizontal trajectory (longitude-latitude) and the actual path of a diving animal. Other studies have also questioned the validity of behavioural interpretations based on a dataset with reduced dimensions (Harcourt et al. 2000, Davis et al. 2003). New technological devices, such as 3D accelerometers and video cameras, are promising ways to resolve these issues. In free-ranging Weddell seals Leptonychotes weddellii for instance, studies using video recordings have provided evidence of encounters of prey during foraging dives (Davis et al. 2003). In Weddell seals and also in captive Steller sea lions Eumetopias jubatus, accelerometers were able to precisely detect the mouth opening events linked with prey capture attempts (Naito et al. 2010, Viviant et al. 2010). Such in situ recording devices can record real behavioural activity and also help to identify accurate 2D proxies of foraging effort. Use of such new devices could therefore validate our findings that active dives are the most successful foraging dives. It is our intention to examine this in future work.

\section{CONCLUSION}

Previous studies have shown that southern elephant seals display various behavioural modes detected from tracking data (Bailleul et al. 2008) and various dive classes during their foraging trips (Hindell et al. 1991, Thums et al. 2008). Here we have shown that proportions of dive classes displayed by southern elephant seal females varied according to 
their horizontal behaviour. It is probable that by going to the polar frontal zone where resources are both spatially and temporally highly variable, female elephant seals can concentrate their foraging/searching activity in the most productive parts of the zone and maximise feeding success. They repeatedly adapt their diving behaviour to prey accessibility in the water column and seem to make a trade-off between diving depth and recovery time. Mass gain over the animals' foraging trips was also highly correlated to the proportion of intensive foraging detected by track-based analyses. Improved body condition of seals was associated with the occurrence, within the vertical dimension, of sets of highly active dives. The classification of diving behaviour is not an end in itself, but rather a tool that allows us to conclude that intensive foraging detected from surface tracking data is a good predictor of the diving activity and foraging success occurring in the vertical dimension. The application of fine-scale monitoring of in situ oceanographic conditions in combination with high resolution behavioural datasets is an interesting avenue for future research into foraging behaviour in relation to prey distribution in changing environments.

Acknowledgements. The authors thank all fieldworkers of the 60th Mission for field work that helped to collect data. This study is part of a national research program (no. 109, $\mathrm{H}$. Weimerskirch and the observatory Mammifères Explorateurs du Milieu Océanique, MEMO SOERE CTD 02) supported by the French Polar Institute (Institut Paul Emile Victor, IPEV). This work was carried out in the framework of IPSOS-SEAL (ANR VMC 07) program and CNES-TOSCA program ('Élephants de mer océanographes'). The authors also thank the Total Fundation for financial support. All animals in this study were cared for in accordance with its guidelines. We are grateful to 3 anonymous reviewers for very useful comments and to Janos Hennicke for correction of the English. Special thanks go also to Matthieu Authier and Frédéric Bailleul for very useful comments and discussions. Finally, the authors thank Ian Jonsen, who provided the state-space model scripts and kind assistance for analysis of the tracking data ( $\mathrm{R}$ and WinBUGS scripts are available on demand to Ian Jonsen).

\section{LITERATURE CITED}

Aarts G, MacKenzie M, McConnell B, Fedak M, Matthiopoulos J (2008) Estimating space-use and habitat preference from wildlife. Ecography 31:140-160

Akaike H (1973) Information theory and an extension of the maximum likelihood principle. In: Petrov BN, Czaki P (eds) Proc 2nd Int Symp Information Theory, Tsahkadsor, Armenia. Akademiai Kiado, Budapest, p 267-281

- Aoki K, Watanabe Y, Crocker D, Robinson P and others (2011) Northern elephant seals adjust gliding and stroking patterns with changes in buoyancy: validation of at-sea metrics of body density. J Exp Biol 214: 2973-2987

Austin D, Bowen W, McMillan J, Boness D (2006) Stomach temperature telemetry reveals temporal patterns of foraging success in a free-ranging marine mammal. J Anim Ecol 75:408-420

Bailleul F, Charrassin J, Ezraty R, Girard-Ardhuin F, McMahon C, Field I, Guinet C (2007a) Southern elephant seals from Kerguelen Islands confronted by Antarctic sea ice. Changes in movements and in diving behaviour. Deep-Sea Res II 54:343-355

Bailleul F, Charrassin J, Monestiez P, Roquet F, Biuw M, Guinet C (2007b) Successful foraging zones of southern elephant seals from Kerguelen Islands in relation to oceanographic conditions. Phil Trans R Soc B 362: 2169-2181

Bailleul F, Pinaud D, Hindell M, Charrassin J, Guinet C (2008) Assessment of scale-dependent foraging behaviour in southern elephant seals incorporating the vertical dimension: a development of the first passage time method. J Anim Ecol 77:948-957

Bailleul F, Authier M, Ducatez S, Roquet F, Charrassin JB, Cherel Y, Guinet C (2010a) Looking at the unseen: combining bio-logging and stable isotopes to reveal a shift in the ecological niche of a deep-diving predator. Ecography 33:709-719

Bailleul F, Cotté C, Guinet C (2010b) Mesoscale eddies as foraging areas of a deep-diving predator, the southern elephant seal. Mar Ecol Prog Ser 408:251-264

Bakun A (2006) Fronts and eddies as key structures in the habitat of marine fish larvae: Opportunity, adaptive response and competitive advantage. Sci Mar 70(S2): 105-122

Berta A, Sumich J, Kovacs K (2006) Marine mammals: evolutionary biology, 2nd edn. Elsevier Academic Press, Amsterdam

- Biuw M, McConnell B, Bradshaw C, Burton H, Fedak M (2003) Blubber and buoyancy: monitoring the body condition of free-ranging seals using simple dive characteristics. J Exp Biol 206:3405-3423

Biuw M, Boehme L, Guinet C, Hindell M and others (2007) Variations in behaviour and condition of a southern ocean top predator in relation to in situ oceanographic conditions. Proc Natl Acad Sci USA 104:13705-13710

Block B, Jonsen I, Jorgensen S, Winship A, Shaffer S, Bograd S (2011) Tracking apex marine predator movements in a dynamic ocean. Nature 475:86-90

Bost C, Cotté C, Bailleul F, Cherel Y and others (2009) The importance of oceanographic fronts to marine birds and mammals of the southern oceans. J Mar Syst 78:363-376

- Bovet P, Benhamou S (1988) Spatial analysis of animals' movements using a correlated random walk model. J Theor Biol 131:419-433

Boyd I, Arnbom T (1991) Diving behaviour in relation to water temperature in the southern elephant seal: foraging implications. Polar Biol 2:259-266

> Bradshaw C, Hindell M, Sumner M, Michael K (2004) Loyalty pays: potential life history consequences of fidelity to marine foraging regions by southern elephant seals. Anim Behav 68:1349-1360

Brillinger D, Stewart B (1997) Elephant seal movements: dive types and their sequences. Gregoire TG et al. (eds) Modelling longitudinal and spatially correlated data: methods, applications, and future directions. Lecture 
notes in statistics, Vol 122. Springer, New York, NY, p 275-288

Burnham K, Anderson D (2002) Model selection and multimodel inference: a practical information-theoretic approach, 2nd edn. Springer-Verlag, New York, NY

Charnov E (1976) Optimal foraging, the marginal value theorem. Theor Popul Biol 9:129-136

> Charrassin J, Kato A, Handrich Y, Sato K and others (2001) Feeding behaviour of free-ranging penguins determined by oesophageal temperature. Proc Biol Sci 268:151-157

Cherel Y, Ducatez S, Fontaine P, Richard P, Guinet C (2008) Stable isotopes reveals the trophic position and mesopelagic diet of female southern elephant seals breeding on the Kerguelen Islands. Mar Ecol Prog Ser 370: 239-247

> Costa D, Kuhn C, Weise M, Shaffer S, Arnould J (2004) When does physiology limit the foraging behaviour of freely diving mammals? Int Congr Ser 1275:359-366

Crocker D, Le Boeuf B, Costa D (1997) Drift diving in female northern elephant seals: implications for food processing. Can J Zool 75:27-39

> Davis R, Fuiman L, Williams T, Le Boeuf B (2001) Three-dimensional movements and swimming activity of a northern elephant seal. Comp Biochem Physiol A 129:759-770

> Davis R, Fuiman L, Williams T, Horning M, Hagey W (2003) Classification of Weddell seal dives based on 3-dimensional movements and video-recorded observations. Mar Ecol Prog Ser 264:109-122

- Dennis B (1996) Discussion: Should ecologists become bayesians? Ecol Appl 6:1095-1103

> Dragon AC, Monestiez P, Bar-Hen A, Guinet C (2010) Linking foraging behaviour to physical oceanographic structures: southern elephant seals and mesoscale eddies east of Kerguelen Islands. Prog Oceanogr 87:61-71

> Ducatez S, Dalloyau S, Richard P, Guinet C, Cherel Y (2008) Stable isotopes document winter trophic ecology and maternal investment of adult female southern elephant seals (Mirounga leonina) breeding at Kerguelen Islands. Mar Biol 155:413-420

Fauchald P (1999) Foraging in a hierarchical patch system. Am Nat 153:603-613

Fedak M, Lovell P, Grant S (2001) Two approaches to compressing and interpreting time-depth information as collected by time depth recorders and satellite-linked data recorders. Mar Mamm Sci 17:94-110

> Field I, Bradshaw C, Burton H, Hindell M (2004) Seasonal use of oceanographic and fisheries management zones by juvenile southern elephant seals (Mirounga leonina) from Macquarie Island. Polar Biol 27:432-440

Field I, Bradshaw C, van den Hoff J, Burton H, Hindell M (2007) Age-related shifts in the diet composition of southern elephant seals expand overall foraging niche. Mar Biol 150:1441-1452

Flierl G, McGillicuddy D (2002) Mesoscale and submesoscale physical-biological interactions. In: Robinson A, McCarthy J, Rothschild B (eds) The sea, Vol 12. John Wiley \& Sons, New York, NY, p 113-185

Forgy EW (1965) Cluster analysis of multivariate data: efficiency vs interpretability of classifications. Biometrics 21: 768-769

> Gille S (2002) Warming of the southern ocean since the 1950s. Science 295:1275-1277

> Harcourt R, Hindell M, Bell D, Waas J (2000) Threedimensional dive profiles of free-ranging Weddell seals. Polar Biol 23:479-487
Hassrick J, Crocker D, Zeno R, Blackwell S, Costa D, LeBoeuf B (2007) Swimming speed and foraging strategies of northern elephant seals. Deep-Sea Res II 54:369-383

Hindell M, Slip D, Burton H (1991) The diving behaviour of adult male and female southern elephant seals, Mirounga leonina (Pinnipedia: Phocidae). Aust J Zool 39: 595-619

Hindell M, McConnell B, Fedak M, Slip D, Burton H, Reijinders P, McMahon C (1999) Environmental and physiological determinant of successful foraging by naive southern elephant seal pups during their first trip to sea. Can J Zool 77:1807-1821

Hunt G, Mehlum F, Russell R, Irons D, Decker M, Becker P (1999) Physical processes, prey abundance and the foraging ecology of seabirds. In: Adams NJ, Slotow RH (eds) Proc 22nd Int Ornithol Congr. BirdLife South Africa, Durban, p 2040-2046

> Jonsen I, Myers R, Mills Flemming J (2003) Meta-analysis of animal movement using state-space models. Ecology 84 : 3055-3063

Jonsen I, Myers R, James M (2007) Identifying leatherback turtle foraging behaviour from satellite telemetry using a switching state-space model. Mar Ecol Prog Ser 337: 255-264

> Jouventin P, Weimerskirch H, (1990) Satellite tracking of wandering albatrosses. Nature 343:746-748

> Kareiva P, Odell G (1987) Swarms of predators exhibit 'preytaxis' if individual predators use area-restricted search. Am Nat 130:233-270

Kotliar N, Wiens J (1990) Multiple scales of patchiness and patch structure: a hierarchical framework for the study of heterogeneity. Oikos 103:153-161

> Le Quéré C, Rodenbeck C, Buitenhuis E, Conway T and others (2007) Saturation of the southern ocean $\mathrm{CO}_{2}$ sink due to recent climate change. Science 316:1735-1738

Le Boeuf B, Costa D, Huntley A, Feldcamp S (1988) Continuous, deep diving in female northern elephant seals, Mirounga angustirostris. Can J Zool 66:446-458

McConnell B, Chambers C, Fedak M (1992) Foraging ecology of southern elephant seals in relation to the bathymetry and productivity of the southern ocean. Antarct Sci 4:393-398

- McIntyre T, de Bruyn P, Ansorge I, Bester M, Bornemann H, Ploetz J, Tosh C (2010) A lifetime at depth: vertical distribution of southern elephant seals in the water column. Polar Biol 33:1037-1048

McIntyre T, Bornemann H, Ploetz J, Tosh C, Bester M (2011) Water column use and forage strategies of female southern elephant seals from Marion Island. Mar Biol 158: 2125-2139

McMahon C, Burton H, McLean S, Slip D, Bester M (2000) Field immobilisation of southern elephant seals with intravenous tiletamine and zolazepam. Vet Rec 146: 251-254

> Meredith M, Hogg A (2006) Circumpolar response of Southern Ocean eddy activity to changes in the Southern Annular Mode. Geophys Res Lett 33:16-20

- Mitani Y, Andrews R, Sato K, Kato A, Naito Y, Costa D (2010) Three-dimensional resting behaviour of northern elephant seals: drifting like a falling leaf. Biol Lett 6: 163-166

Morales J, Haydon D, Frair J, Holsinger K, Fryxell J (2004) Extracting more out of relocation data: building movement models as mixtures of random walks. Ecology 85: 2436-2445 
Naito Y, Bornemann H, Takahashi A, McIntyre T, Ploetz J (2010) Fine-scale feeding behavior of Weddell seals revealed by a mandible accelerometer. Polar Sci 4: 309-316

NGDC (National Geophysical Data Center) (2001) ETOPO-2 Global 2' Elevations. National Oceanic and Atmospheric Administration, US Dept of Commerce, Boulder, CO

Orsi A, Whitworth T III, Nowlin J (1995) On the meridional extent and fronts of the Antarctic circumpolar current. Deep-Sea Res I 42:641-673

Parker G, Stuart R (1976) Animal behaviour as a strategy optimizer: evolution of resource assessment strategies and optimal emigration thresholds. Am Nat 110:1055

Patterson TA, Thomas L, Wilcox C, Ovaskainen O, Matthiopopoulos J (2008) State-space models of individual animal movement. Trends Ecol Evol 23:87-94

Pinheiro J, Bates D (2000) Mixed-effects models in S and S-PLUS. Springer, New York, NY

R Development Core Team (2009) R: a language and environment for statistical computing. R Foundation for Statistical Computing, Vienna

Robinson PW, Simmons SE, Crocker DE, Costa DP (2010) Measurements of foraging success in a highly pelagic marine predator, the northern elephant seal. J Anim Ecol 79:1146-1156

Schick RS, Loarie S, Colchero F, Best B and others (2008) Understanding movement data and movement processes: current and emerging directions. Ecol Lett 11:1338-1350

Schreer J, Testa J (1996) Classification of Weddell seal diving behavior. Mar Mamm Sci 12:227-250

Schreer J, Kovacs K, O'Hara Hines R (2001) Comparative diving patterns of pinnipeds and seabirds. Ecol Monogr 71:137-162

Smetacek V, Nicol S (2005) Polar ocean ecosystem in a changing world. Nature 437:362-368

Editorial responsibility: Hans-Heinrich Janssen,

Oldendorf/Luhe, Germany
Spiegelhalter D, Thomas A, Best N (1999) WinBUGS Version 1.2 user manual. MRC Biostatistics Unit, Cambridge

Sturtz S, Ligges U, Gelman A (2005) R2Winbugs: a package for running WinBUGS from R. J Stat Softw 12:1-16

Thums M, Bradshaw CJ, Hindell MA (2008) Tracking changes in relative body composition of southern elephant seals using swim speed data. Mar Ecol Prog Ser 370:249-261

> Thums M, Bradshaw C, Hindell M (2011) In-situ measures of foraging success and prey encounter reveal marine habitat-dependent search strategies. Ecology 92: 1258-1270

Turchin P (1991) Translating foraging movements in heterogeneous environments into the spatial distribution of foragers. Ecology 72:1253-1266

Venables W, Ripley B (2002) Modern applied statistics with S, 4th edn. Springer, New York, NY

Viviant M, Trites A, Rosen D, Monestiez P, Guinet C (2010) Prey capture attempts can be detected in Steller sea lions and other marine predators using accelerometers. Polar Biol 33:713-719

- Webb P, Crocker D, Blackwell S, Costa D, Le Boeuf B (1998) Effects of buoyancy on the diving behavior of northern elephant seals. J Exp Biol 201:2349-2358

Weimerskirch H, Bonadonna F, Bailleul F, Mabille G, Dell'Omo G, Lipp HP (2002) Gps tracking of foraging albatrosses. Science 295:1259

Weimerskirch H, Pinaud D, Pawlowski F, Bost CA (2007) Does prey capture induce area-restricted search? A finescale study using GPS in a marine predator, the wandering albatross. Am Nat 170:734-743

- Widder E (2010) Bioluminescence in the ocean: origins of biological, chemical, and ecological diversity. Science 328:704

Submitted: May 19, 2011; Accepted: November 14, 2011 Proofs received from author(s): January 31, 2012 